\title{
(อ) OPEN ACCESS \\ Cardiac arrest due to accidental overdose with norepinephrine dissolved in crystalloid
}

\author{
Jan Hansel, ${ }^{1}$ Gunnar Skúli Ármannsson²
}

'Department of Anaesthetics, Blackpool Teaching Hospitals NHS Foundation Trust,

Blackpool, UK

${ }^{2}$ Department of Anaesthesia and Intensive Care, Landspítali University Hospital, Reykjavík, Iceland

\section{Correspondence to \\ Dr Jan Hansel; \\ jan.hansel@nhs.net}

Accepted 16 November 2020

Check for updates

(c) BMJ Publishing Group Limited 2020. Re-use permitted under CC BY-NC. No commercial re-use. See rights and permissions. Published by BMJ.

To cite: Hansel J, Ármannsson GS. BMJ Case Rep 2020;13:e237643. doi:10.1136/bcr-2020237643

\section{SUMMARY}

Vasoactive agents should be administered through a controlled well-marked infusor pump, ideally via a central venous catheter if given over longer periods of time. During transfer of haemodynamically unstable patients with limited staffing and resources on site, a peripheral vasopressor infusion is sometimes resorted to as a temporary measure of optimising haemodynamic parameters. We report a case of accidental norepinephrine overdose after such practice, resulting in cardiac arrest. It illustrates the importance of careful use and labelling of vasoactive agents during the transport and handover of critically ill patients. Finally, we explore human factor issues associated with transfer from the pre-hospital to the in-hospital environment when such preparations are used.

\section{BACKGROUND}

Vasoactive agents should be administered through a controlled well-marked infusor pump, ideally via a central venous catheter if given over longer periods of time. During transport of haemodynamically unstable patients with limited staffing and resources on site, a peripheral vasopressor infusion is sometimes resorted to as a temporary measure of optimising haemodynamics. ${ }^{1}$ The most commonly used vasopressor in such circumstances is diluted epinephrine, where $1 \mathrm{mg}$ of epinephrine $(1: 1000)$ is mixed into a given amount of crystalloid, producing a diluted solution that can be easily titrated. ${ }^{2}$ Other vasoactive substances can be constituted in a similar fashion or as push-dose vasopressors, but such use is highly controversial. We report a case of accidental norepinephrine overdose after such practice, resulting in cardiac arrest. It illustrates the importance of careful use and labelling of vasoactive agents during the transport and hand over of critically ill patients. Finally, it demonstrates the human factor issues associated with transfer from the prehospital to the in-hospital environment when such preparations are used.

\section{CASE PRESENTATION}

A 56-year-old man was transported to a tertiary healthcare facility by aeromedical services after a suicide attempt by co-ingestion of an unknown quantity of tramadol, oxycodone and oral morphine. Due to a decreased respiratory rate and airway compromise, a modified rapid sequence induction with propofol and rocuronium was performed on scene and the patient was endotracheally intubated without complications prior to transport. During fixed-wing transport the patient experienced hypotension refractory to a fluid bolus of $500 \mathrm{~mL}$ Ringer's lactate. Norepinephrine $5 \mathrm{mg}$ was injected into the remaining $500 \mathrm{~mL}$ of crystalloid in the bag and titrated to effect via a roller flow control clamp. The preparation was marked as '+NOR $5 \mathrm{mg} / 500 \mathrm{~mL}$ ' with a ballpoint pen onto the transparent bag without a dedicated label (see figure 1).

On arrival at the receiving emergency department (ED), the patient had stable vital signs, was mechanically ventilated and did not require additional sedation. A standard situation, background, assessment and recommendation handover took place between the aeromedical transfer team, the ED team and the intensive care unit (ICU) registrar, with mention of the diluted vasopressor. Cessation of the pre-hospital norepinephrine infusion was requested verbally by the ICU registrar and stopped by a member of the nursing staff. A new infusor pump formulation of norepinephrine was prepared as per hospital policy and started peripherally in the antecubital fossa at a rate of $0.02 \mu \mathrm{g} / \mathrm{kg} / \mathrm{min}$ via syringe driver in light of the anticipated need for a low dose of norepinephrine to match the solution in the bag of crystalloid. A mean arterial pressure of 65 was targeted clinically. An arterial cannula for invasive blood pressure (IBP) monitoring was inserted at that point. Within minutes the patient became markedly hypertensive with an IBP reading of $230 / 110 \mathrm{~mm} \mathrm{Hg}$ and heart rate of $110 / \mathrm{min}$. The new norepinephrine infusion via syringe driver was stopped immediately, thought to have caused the spike. The patient remained hypertensive during transport to the ICU. A blanching macular rash developed on the front torso, extending up to the right aspect of the neck and head. Rapidly, the patient developed sinus tachycardia at a rate of $150 / \mathrm{min}$. Glyceryl trinitrate was administered intravenously in quick successive boluses of 0.5 $\mathrm{mg}$ up to $2 \mathrm{mg}$ with no response. The patient proceeded to develop frequent premature ventricular complexes (PVC) on the 5-lead ECG monitor, with the IBP reading rising to $315 / 190 \mathrm{~mm} \mathrm{Hg}$ at its highest. At that point the pre-hospital norepinephrine infusion was recognised by a member of the team to be running fully open and immediately stopped and disconnected. The patient experienced further PVCs and approximately $30 \mathrm{~s}$ after cessation of the infusion, the monitor displayed ventricular fibrillation and a flat line on the IBP trace. Cardiac arrest was confirmed, compressions initiated and performed until the defibrillator was available, and return of spontaneous circulation was achieved after a single shock with $200 \mathrm{~J}$. 


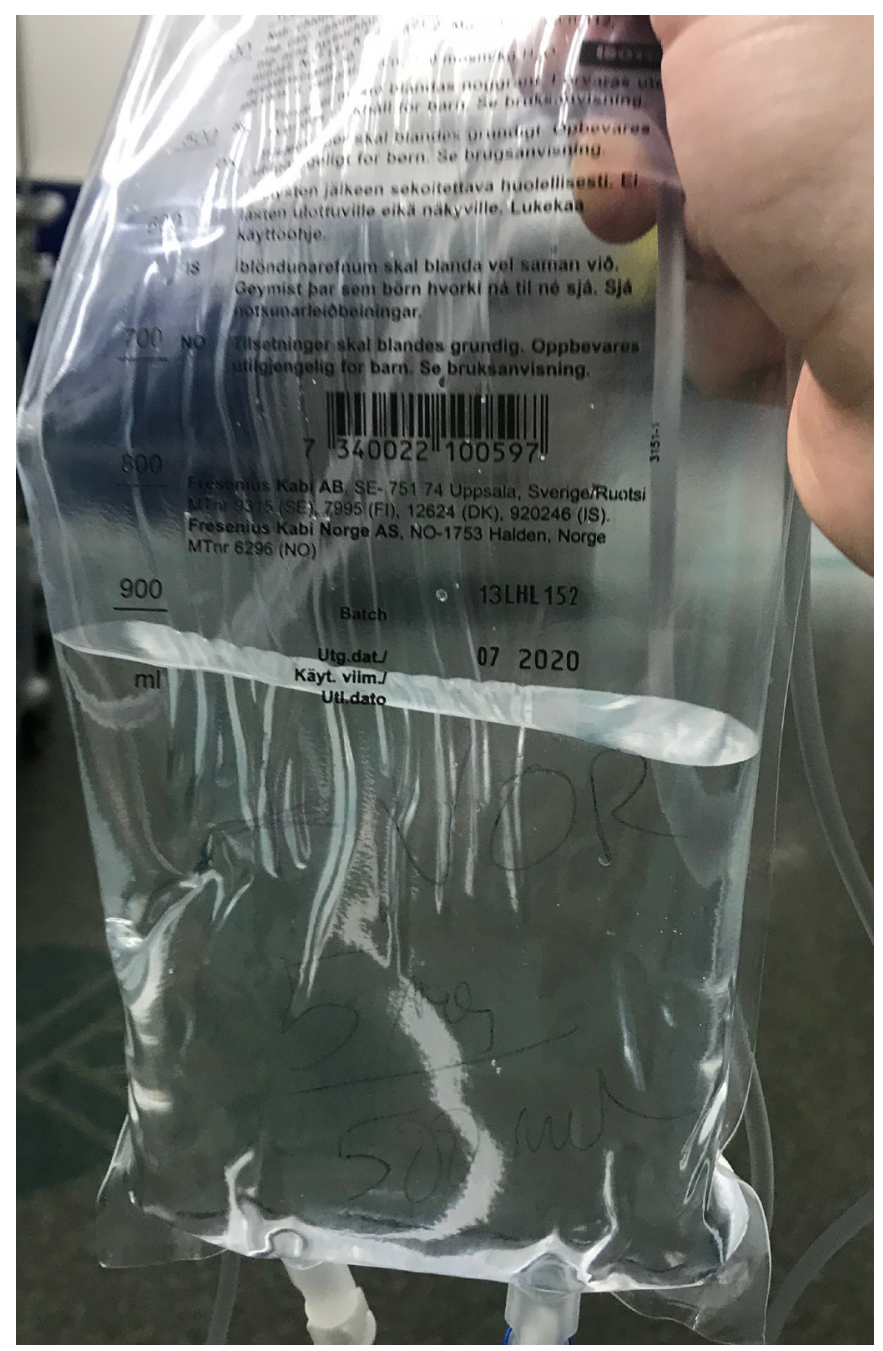

Figure 1 Norepinephrine $5 \mathrm{mg}$ mixed with Ringer's lactate $1000 \mathrm{~mL}$. Note the ballpoint pen marking at the bottom stating '+NOR $5 \mathrm{mg} / 500 \mathrm{~mL}$.'

After cessation of the pre-hospital norepinephrine infusion, the patient stabilised within $10 \mathrm{~min}$ and did not require vasopressor support nor sedation. He received approximately $3 \mathrm{mg}$ of norepinephrine from arrival to the ED over a span of about $20 \mathrm{~min}$ and $4 \mathrm{mg}$ in total, equivalent to a dose of approximately $4 \mu \mathrm{g} \cdot \mathrm{kg}^{-1} \cdot \mathrm{min}^{-1}$. Post-arrest, the patient had marked mydriasis bilaterally with no discernible response to light initially. ECG demonstrated sinus tachycardia with no overt signs of ischaemia. High-sensitivity serial troponin measurements were within normal limits. On stabilisation a non-contrast CT scan of the head was performed to exclude intracranial haemorrhage, which was normal. The patient was extubated later that day and discharged from the ICU on day 2 without neurological or cardiac sequelae for further mental health evaluation.

A hot debrief was performed with the team involved in the patient's care immediately after resuscitation. There was no clear conclusion as to a single cause of the incident, but several factors were highlighted as contributory: a poorly labelled drug dilution, accidental re-initiation of norepinephrine as a bolus by a staff member unaware of the dilution, failure to remove the bag instead of just stopping the infusion and a relatively late recognition of ongoing bolus infusion. The adverse incident was reported and a root cause analysis was performed at a later stage, with all parties from the pre-hospital and in-hospital setting debriefed and action plans implemented to improve future care.

\section{OUTCOME AND FOLLOW-UP}

The patient had a short hospital stay during this admission and was discharged without long-term sequelae.

\section{DISCUSSION \\ Drug labelling}

Drug labelling is a safety measure where non-compliance continues to be implicated in a myriad of cases of drug errors. ${ }^{34}$ It is especially important to have clear labels when a handover of work is expected and as such adherence to good practice standards is the safest approach. ${ }^{5}$ Most international guidelines on product labelling state that bags should be labelled immediately once an injectable is added and should contain a clearly visible sticker with at the very least the substance name, quantity, dilution, date and time. ${ }^{6}$

A matter of some confusion in our case was the marking of $500 \mathrm{~mL}$ on the $1000 \mathrm{~mL}$ bag, with later clarification that the norepinephrine was added after the first $500 \mathrm{~mL}$ had been given. Ideally, a separate infusion from the resuscitation fluid should have been mixed.

The opinions on whether vasoactive substances should be given via a roller flow control clamp at all are divided at best. It can be justified in extreme emergency circumstances (eg, prehospital environment where access to an infusor pump might be limited) only as a temporary measure before at least an elastomeric infusion pump, or ideally a syringe driver infusor can be set up.

\section{Human factors}

There was a clear failure of closed-loop communication in the above case. The pre-hospital diluted norepinephrine was stopped to begin with, until a member of the team, who had not heard the handover data point regarding norepinephrine, opened the roller clamp again after the new syringe driven norepinephrine was being administered, without letting the rest of the team know explicitly. The team leader, unaware of said change, did not factor the old solution into the list of possible causes of the hypertensive emergency, wrongly assuming that the pre-hospital solution had been stopped.

Communication breakdowns and teamwork failures have been identified as key contributing factors in the occurrence of patient safety incidents and have been estimated to result in 1744 deaths in the USA over the span of 5 years, according to a Joint Commission report from 2017. ${ }^{7}$

Protocolised care and the use of a structured checklist has the potential to prevent catastrophic outcomes. ${ }^{8}$ Whereas the operating theatre environment has long since embraced the culture of checklists (eg, WHO Surgical Safety Checklist), they seem harder to implement in acute and unpredictable environments, where multiple time-sensitive interventions need to happen simultaneously to prevent patient harm. ${ }^{9}$ An essential prerequisite for error prevention and risk reduction in such situations is a well-functioning team with clearly defined roles and responsibilities. We noted a breakdown in those as well in this case, as a closed-loop communication style was not adhered to fully with limited oversight over the situation by the ICU registrar, who was assuming the care of the patient. As the team expands with more stakeholders, the lines of responsibility may become blurred even further and this must be guarded against by team leaders. 
In this specific case, a simple institutional policy of discontinuing and discarding all fluids and medical devices from the prehospital transfer team would have likely prevented this adverse incident, if adherence were perfect. The question remains where to implement checklists and policies so as not to impede sensible clinical care and avoid a scapegoating culture, while maximising safety and preventing adverse outcomes. Strides have been made in the pre-hospital and ED setting in larger systems with implementation of checklists for common high-risk scenarios (eg, rapid sequence induction). ${ }^{10}$

Advanced healthcare systems have developed tools and frameworks for implementing a patient safety culture, which consists of organisational commitment, management involvement, employee empowerment, reward systems and reporting systems. There has been a gradual shift from individual to systems failure identification over the past decades. ${ }^{11}$ The Swiss cheese model was proposed by Reason et al. in 1990 and has been a symbol of how systems malfunction when errors occur. The model is still poorly defined and understood by professionals, though, with great variability in the interpretation of its meaning, leading some to question whether it is an appropriate descriptor of organisations prone to errors. ${ }^{12}$

Finally, it is interesting to note that publications on misadventure in healthcare are quite rare outside of public coroner's inquests. Although reporting medical errors to patients is mandatory, no laws or codified guidelines exist on reporting of errors to colleagues. ${ }^{13}$ This usually takes place in the form of debriefings, morbidity and mortality meetings, and root cause analyses, which can translate to institutional memory, but deprives the wider professional community of invaluable learning opportunities.

\section{Learning points}

- Adherence to drug-labelling guidelines can reduce preventable morbidity and mortality.

- Norepinephrine can cause cardiac arrest in a short timespan at moderately toxic doses in humans.

- A deeper understanding of human factors and implementation of sensible safety nets is essential for improving patient care.

Twitter Jan Hansel @virtueofnothing

Acknowledgements We thank Dr Haukur Týr Guðmundsson and Dr Jessica Emerson for their helpful feedback and discussion.

Contributors JH and GSÁ were involved in patient care and jointly wrote the case report. JH wrote the discussion.
Funding The authors have not declared a specific grant for this research from any funding agency in the public, commercial or not-for-profit sectors.

Competing interests None declared.

Patient consent for publication Obtained.

Provenance and peer review Not commissioned; externally peer reviewed.

Open access This is an open access article distributed in accordance with the Creative Commons Attribution Non Commercial (CC BY-NC 4.0) license, which permits others to distribute, remix, adapt, build upon this work non-commercially, and license their derivative works on different terms, provided the original work is properly cited and the use is non-commercial. See: http://creativecommons.org/ licenses/by-nc/4.0/.

\section{REFERENCES}

1 Ekeløf SA, Ekeløf S, Bech JN, et al. [Administration of norepinephrine in peripheral venous catheter on surgical patients]. Ugeskr Laeger 2017;179.

2 Coralic Z. The dirty epi drip: IV epinephrine when you need it. ALiEM, 2013. Available: https://www.aliem.com/dirtyepi/ [Accessed 16 Jun 2020].

3 Jeetu G, Girish T. Prescription drug labeling medication errors: a big deal for pharmacists. J Young Pharm 2010;2:107-11.

4 Elliott RA, Camacho E, Jankovic D, et al. Economic analysis of the prevalence and clinical and economic burden of medication error in England. BMJ Qual SAF, 2020. Available: https://qualitysafety.bmj.com/content/early/2020/05/11/bmjqs-2019010206 [Accessed 19 Jun 2020].

5 Excellence N-TNI for H and C. BNF: British National Formulary - NICE. NICE. Available: https://bnf.nice.org.uk/guidance/guidance-on-intravenous-infusions.html [Accessed 16 Jun 2020]

6 National standard for user-applied labelling of injectable medicines fluids and lines Australian Commission on safety and quality in health care. Available: https://www. safetyandquality.gov.au/our-work/medication-safety/safer-naming-labelling-andpackaging-medicines/national-standard-user-applied-labelling-injectable-medicines fluids-and-lines [Accessed 16 Jun 2020].

7 The Risk Management Foundation of the. CRICO Strategies. Malpractice risk in communication failures; 2015 Annual Benchmarking Report. [Internet]. The Risk Management Foundation of the Harvard Medical Institutions, Inc, 2015. Available: https://www.rmf.harvard.edu/Malpractice-Data/Annual-Benchmark-Reports/Risks-inCommunication-Failures

8 Subbe $C P$, Kellett J, Barach P, et al. Crisis checklists for in-hospital emergencies: expert consensus, simulation testing and recommendations for a template determined by a multi-institutional and multi-disciplinary learning collaborative. BMC Health Serv Res 2017; 17:334.

9 Haynes AB, Weiser TG, Berry WR, et al. A surgical safety checklist to reduce morbidity and mortality in a global population. N Engl J Med 2009;360:491-9.

10 Evaluating Implementation Drivers For The Introduction Of A Greater Manchester Regional Intubation Checklist (B@EASE) |World Airway Management Meeting website - WAMM, 2015. Available: https://www.epostersonline.com/wamm2015/ node/1274 [Accessed 16 Jun 2020].

11 Lo L. Teamwork and Communication in Healthcare: A Literature review [Internet]. Available: https://www.semanticscholar.org/paper/teamwork-and-Communication-inHealthcare-a-review-Lo/b51c00303a81afcda9ae0c32cc4a2bb69fd44a00 [Accessed 16 Jun 2020].

12 Perneger TV. The Swiss cheese model of safety incidents: are there holes in the metaphor? BMC Health Serv Res 2005:5:71.

13 Murphy JG, Stee L, McEvoy MT, et al. Journal reporting of medical errors. Chest 2007;131:890-6.

Copyright 2020 BMJ Publishing Group. All rights reserved. For permission to reuse any of this content visit

https://www.bmj.com/company/products-services/rights-and-licensing/permissions/

BMJ Case Report Fellows may re-use this article for personal use and teaching without any further permission.

Become a Fellow of BMJ Case Reports today and you can:

- Submit as many cases as you like

- Enjoy fast sympathetic peer review and rapid publication of accepted articles

- Access all the published articles

Re-use any of the published material for personal use and teaching without further permission

Customer Service

If you have any further queries about your subscription, please contact our customer services team on +44 (0) 2071111105 or via email at support@bmj.com.

Visit casereports.bmj.com for more articles like this and to become a Fellow 